\title{
Decreased Counterregulatory Hormone Responses to Insulin-Induced Hypoglycemia in Patients with Pancreatic Diabetes Having Autonomic Neuropathy
}

\author{
Teruo Nakamura, Kazuo Takebe, Kenji Kudoh, \\ Masataka Ishit, Ken-IChi Imamura, Hiroaki Kikuchi, \\ Fukio Kasai, Yusuke Tandoh, Naoko Yamada, Yuki \\ Arai, Akinori Terada and KoJi Machida \\ The Third Department of Internal Medicine, Hirosaki \\ University School of Medicine, Hirosaki 036
}

Nakamura, T., Takebe, K., Kudoh, K., Ishit, M., Imamura, K., KikUchi, H., Kasai, F., Tandoh, Y., Yamada, N., Arai, Y., Terada, A. and Machida, K. Decreased Counterregulatory Hormone Responses to Insulin-Induced Hypoglycemia in Patients with Pancreatic Diabetes Having Autonomic Neuropathy. Tohoku J. Exp. Med., 1994, 174 (4), 305-315 — Thrirteen patients with pancreatic diabetes caused by calcifying pancreatitis were divided into 2 groups; 5 with diabetic autonomic neuropathy $[\mathrm{AN}(+)$ group $]$ and 8 without $[\mathrm{AN}(-)$ group $]$. They were subjected to an insulin-induced hypoglycemic stress test to evaluate their blood pancreatic glucagon, adrenalin, and cortisol responses. When a blood glucose level below $45 \mathrm{mg} / 100 \mathrm{ml}$ was defined to be hypoglycemia, all the patients in the $\mathrm{AN}(-)$ group exhibited peripheral adrenalin responses, with a significant increase (mean, 19.0 times the basal level) in the blood adrenalin level. Among the $\mathrm{AN}(+)$ group, on the other hand, central nervous symptoms became evident rather than the peripheral adrenalin response (the blood adrenalin level hardly exceeded the basal level). With the exception of a single patient, none exhibited responses in the blood pancreatic glucagon levels. Only one patient showed a minimal cortisol response but the remaining 12 reacted normally in the cortisol release. The findings are summarized as follows: in pancreatic diabetes, insulininduced hypoglycemia causes little change in pancreatic glucagon secretion; when the condition is complicated with autonomic neuropathy, central nervous symptoms develop while the blood adrenalin level hardly increases. These findings indicated that patients with pancreatic diabetes complicated with diabetic autonomic neuropathy have a risk of lapsing into an acute hypoglycemic coma and difficulty in recovering from the hypoglycemic state._- counterregulatory hormones; insulin-induced hypoglycemia; pancreatic diabetes; autonomic neuropathy

Among the patients who develop diabetes secondary to chronic pancreatitis (i.e., pancreatic diabetes), approximately $30 \%$ of them die from an unknown cause (presumably from hypoglycemia) from midnight to the early morning. The

Received April 4, 1994; revision accepted for publication September 8, 1994. 
characteristics of these patients include the following: all were insulindependent; had been suffering from (painful) peripheral neuropathy; and had often experienced severe hypoglycemic episodes, exhibited poor diabetic control, low body weight, and persisted in drinking alcohol (Nakamura et al. 1987). Moreover, we had experienced a patient with pancreatic diabetes who died from hypoglycemia (blood sugar undetectable) without any cardiovascular changes at autopsy. Some researchers suggested that insulin hypoglycemia is involved in part of the prognosis for patients with pancreatic diabetes (Bank et al. 1975; Linde et al. 1977; Miyake et al. 1989). It has been proven morphologically as well as functionally that these patients suffer from histological changes of Langerhans islet together with pancreatic beta and alfa cell dysfunctions (Pesson et al. 1971; Kalk et al. 1974, 1979; Bank et al. 1975; Okumura et al. 1983; Keller et al. 1984; Domschke et al. 1985). It is believed that diabetic autonomic neuropathy in patients with pancreatic diabetes may provides a dysfunction in adrenalin secretion, compromising the responses to hypoglycemia. This was measured in primary diabetes and not in diabetes secondary to chronic pancreatitis. There have been few reports on the association of pancreatic diabetes with autonomic neuropathy (Deckert 1960). If we are to believe that autonomic neuropathy is associated with pancreatic diabetes, it is expected that the counterregulatory hormone response is suppressed during insulin-induced hypoglycemia. Therefore the present authors divided patients with pancreatic diabetes into two groups according to the involvement of the autonomic neuropathy; and the responses in the blood glucagon, adrenalin, and cortisol levels were examined during insulininduced hypoglycemic stress.

\section{Subjects ANd Methods}

Thirteen patients with calcifying pancreatitis (with pancreatic calcification confirmed by abdominal computed tomography) associated with diabetes mellitus participated in the present study. The details on these patients are listed in Table 1. They were divided into two groups - autonomic neuropathy $[\mathrm{AN}(+)]$ group having diabetic peripheral neuropathy (e.g., loss of Achilles tendon reflex, reduced vibratory sensory perception, and reduced sensory nerve conduction velocity) and having more than 2 of the 5 conditions defining diabetic autonomic neuropathy; 1) gastroparesis (presence of food residue in the stomach, detected by gastric $\mathrm{x}$-ray following 12 hours of fasting after an evening meal), 2) impotence, 3) atonic bladder (a loss of urination sensation or occasional urinary incontinence, often associated with residual urine), and 4) orthostatic hypotension where the most frequent complaints are dizziness, light headedness or a dimming of vision occurring in the first few minutes after arising from a supine or sitting position, syncope upon arising is often preceded by a dimming of vision and a sensation of empty headedness. The above symptoms are subjectively defined as orthostatic hypotension. A drop in systolic blood pressure of $30 \mathrm{mmHg}$ or greater is objec- 
tively defined as postural (orthostatic) hypotension. The presence of cardiac vagal neuropathy was confirmed by computer-associated electrocardiogram analysis (Electrocardiograph-autonomic R-100, NEC, Sanei Instruments, Itd., Tokyo). The heart rate variability (coefficiency variance of R-R intervals (C.V.R-R)) during deep breathing was used for the evaluation of autonomic neuropathy. The $\mathrm{AN}(+)$ group included 5 patients, while 8 belonged to the $\mathrm{AN}(-)$ group. With the exception of 1 , alcoholism was the cause of pancreatitis in the 12 patients. All were men. The mean age of the $\mathrm{AN}(+)$ group was not significantly different from that of the $\mathrm{AN}(-)$ group. The duration of diabetes for the $\mathrm{AN}(+)$ group was 13.4 years, which was not significantly longer than that for the $\mathrm{AN}(-)$ group. There were no significant differences between the $\mathrm{AN}(-)$ and the $\mathrm{AN}(+)$ groups in the laboratory findings (serum albumin, serum total cholesterol and fecal fat excretion). The results of liver function test (GPT) were normal, except in three cases (Cases 1, 2 and 12) who had shown chronic inactive hepatitis by liver biopsy). There were significant differences between the $\mathrm{AN}(-)$ and the $\mathrm{AN}(+)$ groups in both a drop in systolic blood pressure and C.V.R-R as indices of autonomic neuropathy.

Following overnight fasting, $0.1 \mathrm{U} / \mathrm{kg}(0.2 \mathrm{U} / \mathrm{kg}$ if the blood sugar level was high) of Humalin $\mathrm{R}^{\circledR}$ was injected in one shot into a cubital vein and blood specimens were collected before the injection and 20,30,40,50,60,70,80, and 90 min later to determine the blood glucose level (by the glucose oxidase method), the pancreatic glucagon level (Glucagon Kit Daiichi Radioisotope Lab., Tokyo), the adrenalin level (the HPLC method), and the cortisol level (Cortisol Kit Daiichi Radioisotope Lab., Tokyo). To determine the plasma catecholamine levels, the method by Hallman et al. (1978) was modified as follows: $3 \mathrm{ml}$ of a blood sample was added to a test tube containing EDTA-2Na, which was immediately chilled and subjected to centrifugation; the plasma that was separated was then stored in a frozen state at $-20^{\circ} \mathrm{C}$. For the internal standard, 3, 4dihydroxybenzylamine was used. Catecholamines were adsorbed to alumina and extracted in $0.1 \mathrm{M} \mathrm{HClO}_{4}$. For the analysis, HPLC was conducted using a C-18 $4.6 \times 159 \mathrm{~mm}, 5-120-\mathrm{A}$ column (Nippon Bunko Kogyo, Co. Ltd., Tokyo). The procedure was followed by detection using an electrochemical detector (Model 5100A; Nikko Bioscience, Tokyo). C.V. was $2.3 \%(n=10)$ and the yields from the addition tests were found to be satisfactory (94 to $108 \%, n=14$ ).

The development of a hypoglycemic state was judged on the basis of a blood sugar level of $45 \mathrm{mg} / 100 \mathrm{ml}$ or less (Amiel et al. 1987) and/or peripheral nervous symptoms (e.g., palpitation, sweating, sense of uneasiness, tremor, and irritability) or central nervous symptoms (such as a speech disturbance, visual disturbances, and yawning).

Statistical analysis was conducted by Mann-Whitney U test and values were expressed as mean \pm s.E. in figures. 
TABLE 1. Clinical characteristics in patients with pancreatic diabetes

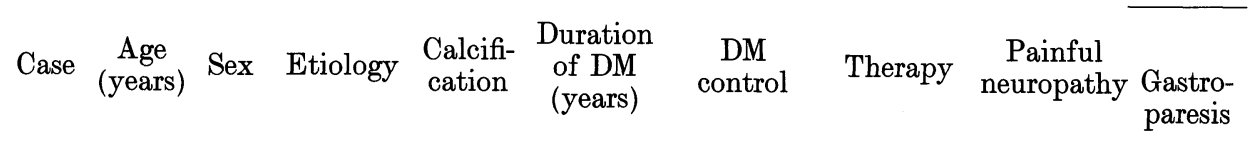

\begin{tabular}{cccccccccc}
\hline 1 & 31 & M & $\begin{array}{c}\text { Pancreas } \\
\text { divisum }\end{array}$ & + & 6 & $10.8 / 9.9$ & Insulin 20U & + & + \\
2 & 52 & M & Alcoholic & + & 11 & $12.4 / 10.5$ & Insulin 44U & + & + \\
3 & 51 & M & Alcoholic & + & 20 & $13.4 / 11.3$ & Insulin 26U & + & + \\
4 & 48 & M & Alcoholic & + & 17 & $11.4 / 9.9$ & Insulin 18U & + & + \\
5 & 55 & M & Alcoholic & + & 13 & $10.5 / 9.5$ & Insulin 22U & + & + \\
\hline Mean & 47.4 & & & & 13.4 & $11.7 \pm 0.53$ & 26 & & \\
\pm S.E. & \pm 4.3 & & & & \pm 2.4 & $/ 10.2 \pm 0.3^{*}$ & \pm 4.7 & & \\
6 & 44 & M & Alcoholic & + & 2 & $8.6 / 5.6$ & Diet & - & - \\
7 & 61 & M & Alcoholic & + & 17 & $12.0 / 10.2$ & Insulin 12U & - & - \\
8 & 64 & M & Alcoholic & + & 10 & $12.1 / 8.2$ & Insulin 28U & - & - \\
9 & 55 & M & Alcoholic & + & 1 & $10.6 / 7.9$ & Diet & - & - \\
10 & 56 & M & Alcoholic & + & 1 & $6.6 / 4.1$ & Diet & - & - \\
11 & 42 & M & Alcoholic & + & 7 & $9.5 / 6.0$ & Insulin 8U & - & - \\
12 & 59 & M & Alcoholic & + & 10 & $10.2 / 9.1$ & Insulin 26U & \pm & - \\
13 & 55 & M & Alcoholic & + & 7 & $11.4 / 10.0$ & Insulin 36U & - & - \\
\hline Mean & 54.5 & & & & 6.9 & $10.1 \pm 0.7$ & 22 & & \\
\pm s.E. & \pm 2.8 & & & & \pm 2.0 & \multicolumn{1}{c}{$/ 7.6 \pm 0.8$} & \pm 5.2 & & \\
\hline
\end{tabular}

BMI, body mass index $\left(\mathrm{kg} / \mathrm{m}^{2}\right)$; Alb, serum albumin $(\mathrm{g} / 100 \mathrm{ml})$; Chol, serum total ${ }^{* *} p<0.01$, Auto $[+]$ vs. Auto $[-]$.

\section{ReSUlts}

Fig. 1 lists the blood sugar, glucagon, adrenalin, and cortisol responses to the insulin-hypoglycemic stress. In the $\mathrm{AN}(+)$ group, the blood glucose level was significantly reduced within $30 \mathrm{~min}$, reaching a minimum level $(46.2 \mathrm{mg} / 100 \mathrm{ml})$ in $70 \mathrm{~min}$. In the $\mathrm{AN}(-)$ group, on the other hand, the blood glucose level was significantly reduced in $20 \mathrm{~min}$ and remained low until $90 \mathrm{~min}$. The minimum blood glucose level of the $\mathrm{AN}(-)$ group was $47.8 \mathrm{mg} / 100 \mathrm{ml}$, which was recorded 50 minutes after the injection. When individual data were examined, the blood sugar level had dropped below $45 \mathrm{mg} / 100 \mathrm{ml}$ in all subjects following insulininduced hypoglycemic stress. However, there were individual differences in the time required for the blood sugar level to reach the minimum ( $30 \mathrm{~min}$ in 3, $40 \mathrm{~min}$ in 3, $50 \mathrm{~min}$ in 2, $60 \mathrm{~min}$ in $2,70 \mathrm{~min}$ in 2 and $90 \mathrm{~min}$ in 1 ).

Therefore the mean minimal level was computed to be larger than $45 \mathrm{mg} / 100$ 
with and without autonomic neuropathy

\begin{tabular}{|c|c|c|c|c|c|c|c|c|c|}
\hline \multicolumn{5}{|c|}{ Autonomic disturbances } & \multirow[b]{2}{*}{$\underset{\left(\mathrm{kg} / \mathrm{m}^{2}\right)}{\mathrm{BMI}}$} & \multicolumn{4}{|c|}{ Laboratory findings } \\
\hline Impotence & $\begin{array}{l}\text { Atonic } \\
\text { bladder }\end{array}$ & $\begin{array}{l}\text { Orthostatic } \\
\text { hypotension } \\
\text { (subjective) }\end{array}$ & $\begin{array}{l}\text { Drop in } \\
\text { systolic } \\
\text { pressure } \\
\text { (mmHg) } \\
\text { (objective) }\end{array}$ & C.V.R-R & & $\begin{array}{c}\text { Alb } \\
(\mathrm{g} / \\
100 \mathrm{ml})\end{array}$ & $\begin{array}{c}\text { Chol } \\
(\mathrm{mg} / \\
100 \mathrm{ml})\end{array}$ & $\begin{array}{l}\text { GPT } \\
(\mathrm{U})\end{array}$ & $\begin{array}{l}\text { Fecal fat } \\
\text { (g/day) }\end{array}$ \\
\hline+ & + & + & 44 & 1.16 & 17.9 & 2.1 & 166 & 62 & n.m. \\
\hline+ & + & + & 30 & 0.82 & 23.4 & 2.0 & 91 & 73 & n.m. \\
\hline+ & - & + & 38 & 1.28 & 20.4 & 4.4 & 144 & 21 & 7.7 \\
\hline+ & - & + & 50 & 2.01 & 18.2 & 3.5 & 133 & 20 & 10.0 \\
\hline \multirow[t]{2}{*}{+} & - & + & 22 & 1.10 & 17.0 & 3.7 & 150 & 30 & 7.5 \\
\hline & & & $\begin{array}{l}36.8^{* *} \\
\pm 5.0\end{array}$ & $\begin{array}{l}1.27^{* *} \\
\pm 0.2\end{array}$ & $\begin{array}{r}19.4 \\
\pm \quad 1.2\end{array}$ & $\begin{array}{r}3.1 \\
\pm 0.5\end{array}$ & $\begin{array}{r}136.8 \\
\pm 12.6\end{array}$ & $\begin{array}{r}41.2 \\
\pm 11.0\end{array}$ & $\begin{array}{r}8.4 \\
\pm 0.8\end{array}$ \\
\hline- & - & - & 12 & 3.1 & 18.3 & 4.3 & 172 & 18 & 16.0 \\
\hline- & - & - & 10 & 2.9 & 18.4 & 1.9 & 65 & 24 & 46.4 \\
\hline- & - & - & 7 & 3.6 & 18.3 & 3.8 & 253 & 21 & n.m. \\
\hline- & - & - & 3 & 2.2 & 21.1 & 4.2 & 236 & 28 & 4.0 \\
\hline- & - & - & 12 & 3.4 & 18.3 & 3.5 & 142 & 20 & 6.5 \\
\hline- & - & - & 8 & 2.8 & 20.3 & 3.9 & 135 & 22 & 7.1 \\
\hline \pm & - & - & 6 & 4.0 & 22.2 & 3.7 & 183 & 63 & 2.5 \\
\hline \multirow[t]{2}{*}{ \pm} & - & - & 0 & 3.0 & 17.2 & 3.3 & 113 & 21 & 25.0 \\
\hline & & & $\begin{array}{r}7.3 \\
\pm 1.5\end{array}$ & $\begin{array}{ll} & 3.13 \\
\pm & 0.2\end{array}$ & $\begin{array}{r}19.3 \\
\pm 0.6\end{array}$ & $\begin{array}{r}3.6 \\
\pm 0.3\end{array}$ & $\begin{array}{r}162.4 \\
\pm 22.1\end{array}$ & $\begin{array}{r}27.1 \\
\pm 5.2\end{array}$ & $\begin{array}{r}15.4 \\
\pm 6.0\end{array}$ \\
\hline
\end{tabular}

cholesterol $(\mathrm{mg} / 100 \mathrm{ml})$; n.m., not measured; ${ }^{*} p<0.05$, Auto $[+]$ vs. Auto $[-]$;

ml. All individuals of the $\mathrm{AN}(-)$ group reported subjective experiences of palpitation, sweating, tremor, anxiety, and hunger. The individuals of the $\mathrm{AN}(+)$ group experienced these sensations very slightly (if at all); but 3 suffered from a speech disturbance and the other reported reduced visual acuity and somnolence.

In the $\mathrm{AN}(-)$ group, significant increases of pancreatic glucagon over the basal level were noted in 60 and $80 \mathrm{~min}$. However, no significant difference was recognized in the glucagon concentrations between the two groups. It should be noted that one individual (Case 10) in the $\mathrm{AN}(-$ ) group exhibited a normal response in the glucagon level (doubling the basal level).

The $\mathrm{AN}(+)$ group exhibited little adrenalin response to the insulin-induced hypoglycemic stress. The $\mathrm{AN}(-)$ group, on the other hand, showed a significant increase in the blood adrenalin level from 50 to 90 min, compared with the $\mathrm{AN}(+)$ group. 


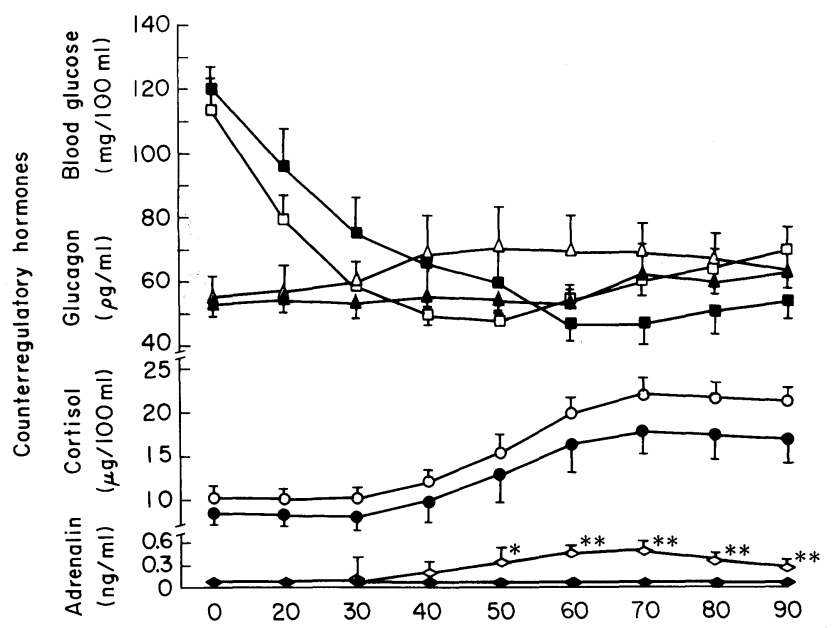

Fig. 1. Counterregulatory hormones response to insulin-induced hypoglycemia in patients with pancreatic diabetes with and without autonomic neuropathy. auto $(+)$ : with autonomic neuropathy; auto $(-)$ : without autonomic neuropathy; - BG-auto (+); $\square-\square$ BG-auto (-); $\square$ - Glucagon-auto $(+) ; \triangle \longrightarrow \triangle$ Glucagon-auto $(-) ; \bullet \longrightarrow$ Cortisol-auto $(+) ; \bigcirc-\bigcirc$ Cortisolauto $(-) ; \diamond$ Adrenalin-auto $(+) ; \diamond \prec$ Adrenalin-auto $(-)$. ${ }^{*} p<0.05 ;{ }^{* *} p<0.01$. Mean \pm s.E.

Cortisol response to insulin-induced hypoglycemia showed similar profile between the two groups. However, one individual (Case 2) of the $\mathrm{AN}(+)$ group showed a basal cortisol level of $3.7 \mathrm{mg} / 100 \mathrm{ml}$ and a peak level of $6.4 \mathrm{mg} / 100 \mathrm{ml}$, indicating the presence of a mild adrenal cortex dysfunction.

The ratio of the maximum rise of each hormone over the basal level in response to insulin-induced hypoglycemia was computed for individuals and the results were plotted in Fig. 2. The rise in the pancreatic glucagon was 1.2 times in the $\mathrm{AN}(+)$ group and 1.5 times in the $\mathrm{AN}(-)$ group, with no significant difference between the two groups. The blood adrenalin level, on the other hand, rose to 2.4 times the basal level in the $\mathrm{AN}(+)$ group; but the $\mathrm{AN}(-)$ group showed an 19.0 times increase, with the latter being a significant increase in contrast to the former. The blood cortisol level rose to 2.1 times in the $\mathrm{AN}(+)$ group and to 2.5 times in the $\mathrm{AN}(-)$ group, with no significant difference between the two.

\section{Discussion}

The present authors divided patients with pancreatic diabetes into 2 groups; those with and without autonomic neuropathy. An insulin-induced hypoglycemic test was conducted and the responses of counterregulatory hormones (such as blood pancreatic glucagon, cortisol, and adrenalin) were observed.

For the insulin-induced hypoglycemic stress, 0.1 to $0.2 \mathrm{U}$ per $\mathrm{kg}$ of body 


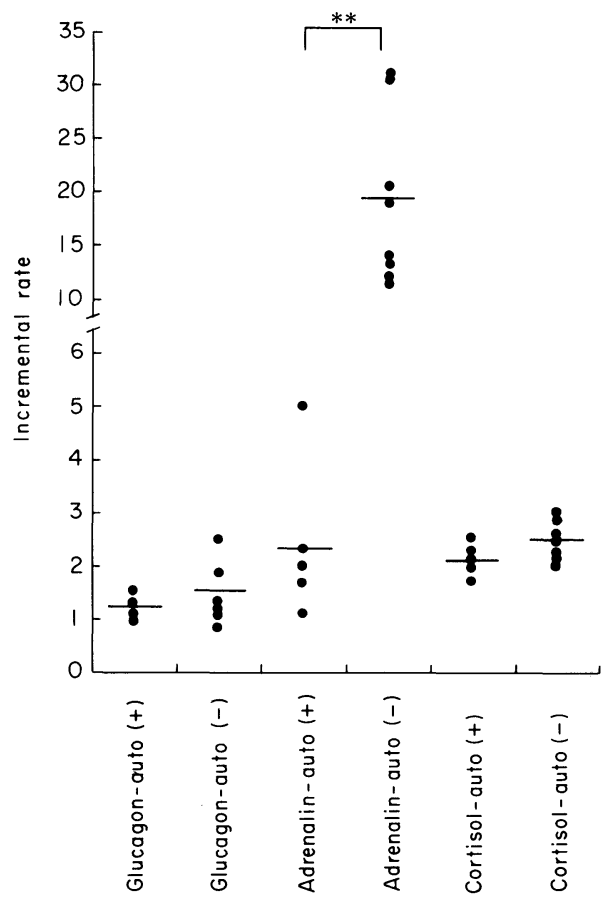

Fig. 2. Maximal incremental rates of counterregulatory hormones to insulininduced hypoglycemia in patients with pancreatic diabetes with autonomic neuropathy. ${ }^{* *} p<0.01$.

weight of Humalin $\mathrm{R}^{\circledR}$ was injected intravenously in one shot. Subsequently, the blood sugar level was reduced below $45 \mathrm{mg} / 100 \mathrm{ml}$ (Amiel et al. 1987) in all within 20 to $70 \mathrm{~min}$ and peripheral adrenalin responses such as palpitation, tremor, and sweating (Renolds et al. 1977) developed in the $\mathrm{AN}(-)$ group. In the $\mathrm{AN}(+)$ group, on the other hand, the above-listed subjective symptoms were mild in spite of the reduced blood glucose level; but they developed central nervous symptoms such as speech and visual disturbances and somnolence (O'Brien et al. 1991). Therefore it was believed that the insulin-induced hypoglycemic stress test was effective in all of the patients with pancreatic diabetes.

It has been noted in histological examinations that the pancreatic Langerhans islets are embedded in the fibrosing pancreas of patients with pancreatic diabetes and that the cells are partly destroyed or have disappeared. The functions of both the alpha and beta cells are markedly reduced and this beta cell dysfunction in pancreatic diabetes results in insulin hyposecretion that simulates insulindependent diabetes mellitus (IDDM) (Schafmeyer et al. 1985; Rämö et al. 1989). Furthermore, pancreatic exocrine and endocrine dysfunctions progress, paralleling each other (Kalk et al. 1979; Keller et al. 1984; Domschke et al. 1985), markedly affecting glucagon secretion (Pesson et al. 1971; Kalk et al. 1974; Okumura et al. 
1983; Keller et al. 1984). As reported previously, the glucagon response was not recognized in either the $\mathrm{AN}(+)$ or $\mathrm{AN}(-)$ group (with one exception) of the patients with pancreatic diabetes in the present study. It has been reported that insulin-induced hypoglycemic stress causes increases in the pancreatic glucagon level 2 to 4 times that of the basal level in normal individuals (Gerich et al. 1974; Horie et al. 1984). Therefore we believe that the aforementioned alpha cell dysfunction is a major feature of pancreatic diabetes, differentiating it from primary diabetes mellitus (Sjoberg and Kidd 1989). It is conceivable that a combination of factors is involved, such as altered pancreaticoportal flow, impaired nerve innervation of islet cell, or impaired paracrine regulatory mechanism involving other islet cells (Yeo et al. 1989). In fact, Larsen have found that a significantly higher concentration of somatostatin during stimulation and after meal. They speculated that increased circulatory somatostatin may contribute to glucoregulation in pancreatic diabetes without endogenous insulin production, by an inhibitory effect on glucagon secretion (Larsen et al. 1988).

It has also been reported that the adrenalin response to hypoglycemic stress is normal in IDDM if the onset of the illness is relatively recent (Bolli et al. 1983). If complicated with an autonomic neuropathy, however, the adrenalin response is minimized and hypoglycemic symptoms are unlikely to develop (Boden et al. 1981). It has been reported that insulin-induced hypoglycemia causes a 5 to 20 times increase in the blood adrenalin concentration over the basal level in normal individuals (Hoeldtke et al. 1982; Polonsky et al. 1982; White et al. 1983; Horie es al. 1984; Amiel et al. 1987). The increase in the adrenalin response in the $\mathrm{AN}(-)$ group of the present study amounted to 19.0 times the basal level, proving that the adrenalin secretory function is intact in this group. The adrenalin response of the $\mathrm{AN}(+)$ group, on the other hand, amounted to only 2.4 times the base level. When the blood glucose level is markedly reduced, the glucoreceptor that is located in the hypothalamus is activated (Mayer and Arees 1968), thus activating the peripheral sympathetic nerves through the neural pathway. The resultant noradrenalin secretion causes the release of adrenalin from the adrenal medulla (Himsworth 1970). The rise in the blood adrenalin level results in sweating, palpitation, and tremulousness (Renolds et al. 1977; Hoeldtke et al. 1982). In our study also, these symptoms were observed in all patients of the $\mathrm{AN}(-)$ group during insulin-induced hypoglycemia. In the $\mathrm{AN}(+)$ group, on the other hand, the central nervous symptoms were dominant and only the so-called prodromal symptoms of hypoglycemic coma (Boden et al. 1981; O'Brien et al. 1991) were recognized.

With one exception, the remaining 4 patients with pancreatic diabetes in the $\mathrm{AN}(+)$ group indicated generally normal cortisol responses. It has been pointed out that the blood cortisol level may be reduced in individuals who consume large quantities of alcohol (Chakmers et al. 1978), but the reason for this phenomenon is unknown. We cannot deny the possibility that diabetic autonomic neuropathy 
is involved in cortisol release. On the other hand, it has generally been believed that the recovery from insulin-induced hypoglycemia primarily requires pancreatic glucagon (Clarke et al. 1979; Rizza et al. 1979; Bolli et al. 1983; Horie et al. 1984), and the adrenalin response is of secondary importance. It has been noted, however, that adrenalin has an important role in the recovery from a hypoglycemic state when pancreatic glucagon secretion is suppressed by somatostatin or an alpha- or beta-adrenergic blocker (Clarke et al. 1979).

The findings given above indicate that the glucagon secretory response to insulin-induced hypoglycemic stress is markedly disturbed in patients with pancreatic diabetes mellitus. It also became evident that when pancreatic diabetes is complicated with autonomic neuropathy, the adrenalin response is also markedly disturbed, that the patients have a risk of lapsing into a sudden coma, and that their ability to recover from the hypoglycemic state is hampered.

\section{References}

1) Amiel, S.A., Simonson, D.C., Tamborlane, W.V., De Fronzo, A. \& Scherwin, S. (1987) Rate of glucose fall does not affect counterregulatory hormone responses to hypoglycemia in normal and diabetic human. Diabetes, 36, 518-522.

2) Bank, S., Marks, I.N. \& Vinik, A.I. (1975) Clinical and hormonal aspects of pancreatic diabetes. Am. J. Gastroenterol., 64, 12-22.

3) Boden, G., Reichard, G.A., Jr., Hoeldtke, R.D., Rezvani, I. \& Owen, O.E. (1981) Severe insulin-induced hypoglycemia associated with deficiencies in the release of counterregulatory hormones. N. Engl. J. Med., 12, 1200-1205.

4) Bolli, G., De Feo, P., Compagnucci, P., Cartechini, M.G., Angelletti, G., Santeusanio, F., Brunetti, P.\& Gerich, J.E. (1983) Abnormal glucose counterregulation in insulin-dependent diabetes mellitus. Diabetes, 32, 134-141.

5) Chakmers, R.J., Bennie, E.H., Johnson, R.H. \& Masterton, G. (1978) Growth hormone, prolactin, and corticosteroid responses to insulin hypoglycemia in alcoholics. Br. Med. J., 1, 745-748.

6) Clarke, W.L., Santiago, J.V., Thomas, L., Haymond, M.W., Ben-Calim, E. \& Cryer, P.E. (1979) The role of adrenergic mechanisms in recovery from hypoglycemia in man: Studies with adrenergic blackade. Am. J. Physiol., 236, E147-E152.

7) Deckert, T. (1960) Late diabetic manifestations in "pancreatogenic" diabetes mellitus. Acta Med. Scand., 168, 439-446.

8) Domschke, S., Stock, K.P., Pichl, J., Schneider, M.U. \& Domschke, W. (1985) Betacell capacity in chronic pancreatitis. Hepatogastroenterology, 32, 27-30.

9) Gerich, J.E., Schneider, V., Dipple, S.E., Langlois, M., Noacco, C., Karam, J.H. \& Forsham, P.H. (1974) Characterization of the glucagon response to hypoglycemia in man. J. Clin. Endocrinol. Metab., 38, 77-82.

10) Hallman, H., Farnebo, L. \& Hamberger, B. (1978) A sensitive method for the determination of plasma catecholamines using liquid chromatography with electrochemical detection. Life. Sci., 123, 1049-1052.

11) Himsworth, R.L. (1970) Hypothalamic control of adrenalin secretion in response to insufficient glucose. J. Physiol. (Lond.), 206, 411-417.

12) Hoeldtke, R.D., Boden, G., Shuman, C.R. \& Owen, D.E. (1982) Reduced epinephrine secretion and hypoglycemia unawareness in diabetic autonomic neuropathy. Ann. Intern. Med., 96, 459-463.

13) Horie, H., Matsuyama, T., Namba, M., Itoh, H., Nonaka, K., Tarui, S., Yamatodani, A. \& Wada, H. (1984) Responses of catecholamines and other counterregulatory 
hormones to insulin-induced hypoglycemia in totally pancreatectomized patients. $J$. Clin. Endocrinol. Metab., 59, 1193-1196.

14) Kalk, W.J., Vinik, A.I., Bank, S., Buchman, K.D., Keller, P.\& Jackson, W.P.U. (1974) Glucagon responses to arginine in chronic pancreatitis. Diabetes, 23, 257263.

15) Kalk, W.J., Vinik, A.I., Jackson, W.P.U. \& Bank, S. (1979) Insulin secretion and pancreatic exocrine function in patients with chronic pancreatitis. Diabetologia, 16, $355-358$.

16) Keller, U., Szöllöy, E., Varga, L. \& Gyr, K. (1984) Pancreatic glucagon secretion and exocrine function (BT-PABA test) in chronic pancreatitis. Dig. Dis. Sci., 29, 853857.

17) Larsen, S., Hilsted, J., Tronier, B. \& Worning, H. (1988) Pancreatic hormone secretion in chronic pancreatitis without residual beta-cell function. Acta Endocrinol., 118, 357-364.

18) Linde, J., Nilsson, L.H. \& Bárány, F.R. (1977) Diabetes and hypoglycemia in chronic pancreatitis. Scand. J. Gastroenterol., 13, 369-373.

19) Mayer, J.\& Arees, E.A. (1968) Ventromedial glucoreceptor system. Fed. Proc., 27, $1345-1348$.

20) Miyake, H., Harada, H., Ochi, K., Kunichika, K., Tanaka, J. \& Kimura, I. (1989) Prognosis and prognostic factors in chronic pancreatitis. Dig. Dis. Sci., 34, 449-455.

21) Nakamura, T., Imamura, K., Tsushima, F., Kawagishi, T., Sekino, K., Kasai, F. \& Takabe, K. (1987) Causes of death of patients with chronic calcifying pancreatitis. Intractable Pancreatic Diseases from the Ministry of Health and Welfare of Japan. pp. 161-163.

22) O'Brien, I.A., McFadden, J.P. \& Corral, R.J.M. (1991) The influence of autonomic neuropathy on mortality in insulin-dependent diabetes. Quar. J. Med., 79, 495-502.

23) Okumura, N., Hayakawa, T., Sakakibara, A., Noda, A. \& Kondo, T. (1983) Plasma pancreatic glucagon response to blood glucose in experimental pancreatolithiasis in dogs. Diabetologia, 25, 510-513.

24) Pesson, I., Gyntelberg, F., Heding, L.G. \& Boss-Nielsen, J. (1971) Pancreaticglucagon-like immunoactivity after intravenous insulin in normals and chronicpancreatitis patients. Acta Endocrinol., 67, 401-404.

25) Polonsky, K., Bergenstal, R., Pons, G., Schneider, M., Jaspan, J. \& Rubenstein, A. (1982) Relation of counterregulatory responses to hypoglycemia in type I diabetics. N. Engl. J. Med., 307, 1106-1112.

26) Rämö, O.J., Puolakkainen, P.A., Seppälä, K. \& Schröder, T.M. (1989) Selfadministration of enzyme substitution in the treatment of exocrine pancreatic insufficiency. Scand. J. Gastroenterol., 24, 688-692.

27) Renolds, C., Molner, G.D., Horwitz, D.L., Rubenstein, A.H., Taylor, W.F. \& Jiang, N.-S. (1977) Abnormalities of endogenous glucagon and insulin in unstable diabetes. Diabetes, 26, 36-45.

28) Rizza, R.A., Cryer, P.E. \& Gerich, J.E. (1979) Role of glucagon, catecholamines, and growth hormone in human glucose counterregulation: Effects of somatostatin and combined $\alpha$-and $\beta$-adrenergic blockade on plasma glucose recovery and glucose flux rates following insulin-induced hypoglycemia. J. Clin. Invest., 64, 62-71.

29) Schafmeyer, A., Becker, H.D., Werner, M., Fölsch, U.R. \& Creutzfeldt, W. (1985) Plasma cholecystokinin levels in patients with chronic pancreatitis. Digestion, 32, 136-139.

30) Sjoberg, R.J. \& Kidd, G.S. (1989) Pancreatic diabetes mellitus. Diabetes Care, 12, $715-724$.

31) White, N.H., Skor, D.A., Cryer, P.E., Levandoski, L.A., Bier, D.M. \& Santiago, J.V. (1983) Identification of type I diabetic patients at increased risk for hypoglycemia during intensive therapy. N. Engl. J. Med., 308, 485-491. 
32) Yeo, C.J., Bastidas, J.A., Schmieg, R.E., Jr., Walfisch, S., Course, N., Olson, J.L., Andersen, D.K. \& Zinner, M.J. (1989) Pancreatic structure and glucose tolerance in a longitudinal study of experimental pancreatitis-induced diabetes. Ann. Surg., 210, $150-158$. 